\title{
Overview of predictive CSP spread prospects and its opportunities
}

\author{
Kai Timon Busse
}

Frank Dinter*

Solar Thermal Energy Research Group, Department of Mechanical and Mechatronic Engineering, University of Stellenbosch, Matieland 7602, South Africa

\begin{abstract}
An investigation was carried out to illustrate the prospects and challenges associated with implementation of concentrating solar power (CSP) with storage technology in South Africa. Various factors were examined that have an effect on the cost of CSP plants and offer an overall review of the opportunities CSP has for the country. This paper appeals the general idea that CSP is not cost effective enough and attempts to illustrate the feasibility of this technology in South Africa.
\end{abstract}

Keywords: concentrating solar power, South Africa, spread scenarios, storage technology

\footnotetext{
* Corresponding author: Tel: +27 (0)21 8084024

Email frankdinter@sun.ac.za

DOI: http://dx.doi.org/10.17159/2413-3051/2016/v27i2a1341
}

\section{Introduction}

Through the last 20 years South Africa has faced numerous power supply problems, especially in late 2007 when there were several rolling power blackouts. As a result, South Africa's Department of Energy (DoE) published the Integrated Resource Plan 2010-30 (IRP) in March 2011, aiming to establish a mix of renewable energy supplies. The IRP attempts to promote steady progress towards an efficient and sustainable power supply for South Africa. The updated 2013 IRP proposed expanding the renewables section to meet nearly $25 \%$ of South Africa's energy demand by 2030.

In a first attempt to facilitate this energy supply shift, the DoE introduced the Renewable Energy Independent Power Producer Procurement (REIPPP) programme (Robb \& Roberts, 2014), which allows individual bidders to bring their contribution by placing tariff bids on the energy supply objectives of the department. Despite strong support for this initiative as an economically reasonable means of promoting renewable energy in South Africa, this paper reviews the CSP capacity allocated within this framework. Sections 4, 5 and 6 illustrate the advantages of CSP over its energy supply competitors.

The IRP's ambitious modification of South Africa's electricity infrastructure may not be strictly perceived as a challenge, but could present an opportunity for the country, given its natural high solar radiation and the potential of such an innovative modification. Closer examination makes it obvious that a restructuring of the South African energy system is inevitable. Grobbelaar et al. (2014: 490) summarise the current situation well: 'CSP is a young technology and there is still space in the global market for South Africa to become involved in technology development and largescale manufacturing.' 


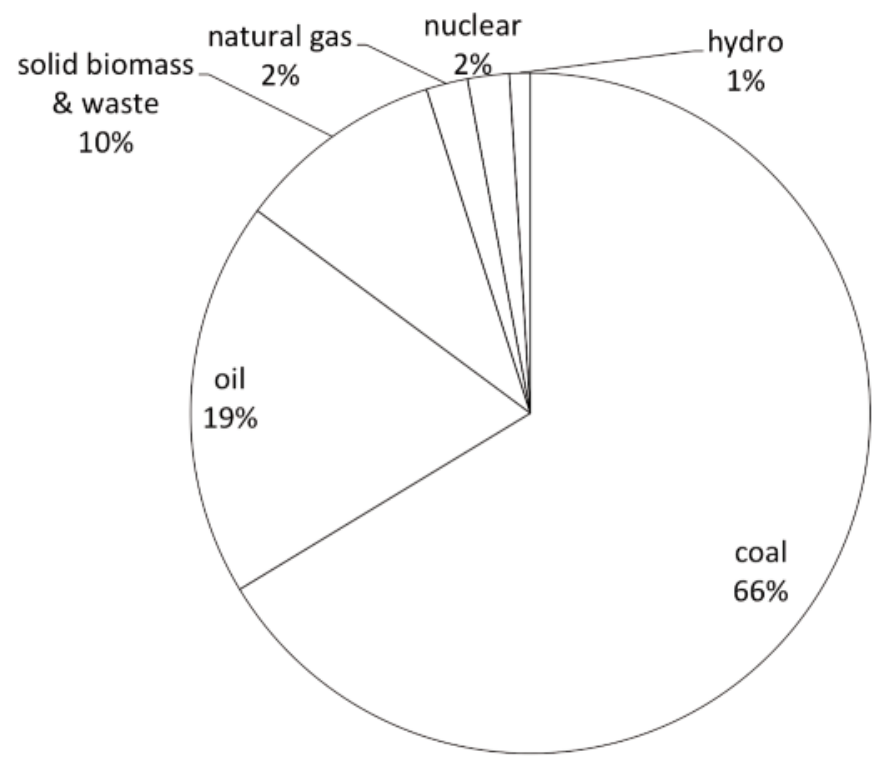

Figure 1: The South African energy mix 2013 Source: Adapted from BP (2013)

Figure 1 shows that the current energy mix in South Africa is dominated by coal. A large proportion of electricity is generated by means of oil used for peak power in open cycle gas turbines. In a scenario where South Africa tolerates fossil fuels, the cost of energy is likely to increase quickly because of decreasing fossil fuel reserves and rising prices. Scenarios envisaging an infrastructural rollout for natural gas imports were made in the updated IRP version (DoE, 2011; 2013a; 2013b). The Mozambican gasfields (Temane and Pande) could deliver what is believed to be a sustainable energy source, although carbon tax costs are likely to be a more pressing issue in the future. An insistence on conventional energy sources could result in dependency on other countries (with possible negative impacts, as in Ukraine, which is currently suffering from its dependency on Russian gas supplies). The consequences must therefore be properly considered, and a near-future turnaround is most desirable in order to acquire a solid position in the global renewable energy market.

In the updated IRP, the CSP is allocated only $1.3 \%$ of the generating capacity by the end of the planning period and not considered a suitable electricity source for the future construction of power plants (DoE, 2011; 2013a; 2013b). This is most likely a result of the current levelised cost of electricity (LCOE). At the moment the LCOE of CSP is much more expensive than other intermediate- or base-load energy supply technologies (e.g. ZAR2.0/kWh for a CSP plant (Nersa, 2011)). It is often forgotten, however, that solar technologies and specifically CSP - offer numerous benefits for South Africa. Figure 2 illustrates typical demand curves for summer and winter days. For winter, the graph displays two power peaks, one in the morning and one in the evening, which reflect challenges associated with inadequate supply that are likely to result in higher power prices. To restore market balance it is necessary to provide a supply curve approximated to the demand, and in order to meet these power peaks, peak power plants (see Pegels, 2010) are required.

A conventional photovoltaic $(\mathrm{PV})$ system generates electricity only while the sun is shining, making it impractical to meet the average electricity demand. During the evening peak, when most power is required, the power network is in need of a flexible and sustainable electricity source. Currently, peak demands are met by several opencycle gas turbines (OCGTs) which make use of expensive electricity generation technologies with a LCOE up to ZAR 5/kWh. In 2014, Eskom was forced to spend ZAR 10.5 billion on diesel fuel to enable the OCGTs, which contributed 3621 GWh of the $230938 \mathrm{GWh}$ produced by the coal-heavy utility (Creamer, 2014). As part of an alternative solution to this problem, CSP could significantly contribute to South Africa's future energy mix.

\section{Concentrating solar power technology}

In contrast to photovoltaic or wind energy, CSP is able to store thermal energy (normally by means of liquid salt in a two-tank system), which can provide electricity after sunset. Concerning cost- and energy-efficiency aspects, thermal energy storage has an advantage over electrical, chemical or potential energy storage systems. Despite the technical experience with wind and $\mathrm{PV}$ plants, CSP is the only established energy source with an efficient combination of energy generation and energy storage (Viebahn et al., 2011). This uniqueness makes CSP potentially valuable for South Africa. Due to its capability to supply electricity when needed, it is possible to provide the necessary grid stability and 


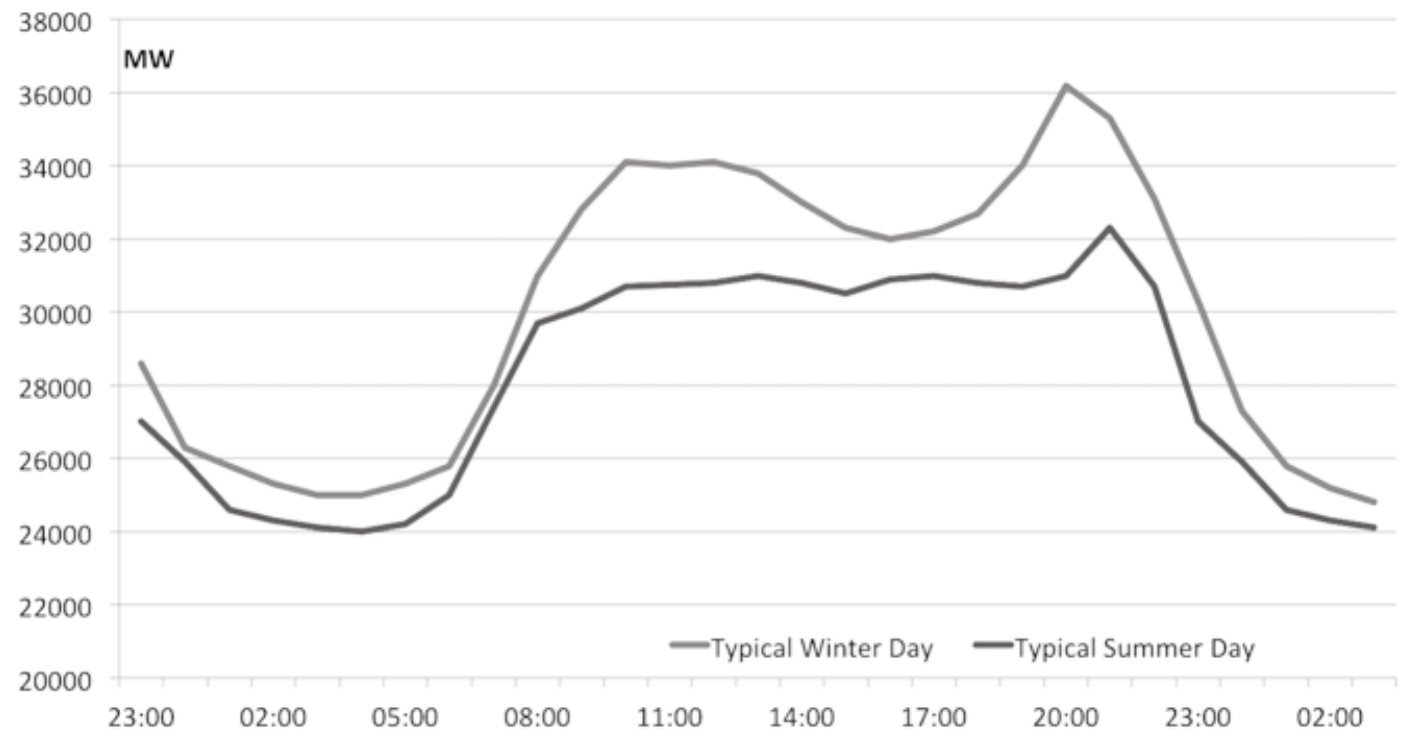

Figure 2: Demand of typical winter and summer days in South Africa Source: Eskom (2014)

flexibility required to meet South Africa's peak demand. The dispatchable nature of the technology makes CSP preferable to other renewables.

A solar thermal power plant usually consists of three major components, namely the solar field, a conventional power block, and an energy storage system. The technology can be classified into two general types of CSPs: line-focus and point-focus.

\subsection{Parabolic trough technology}

Parabolic trough technology focuses sunlight on a receiver pipe (line-focus), which contains a heat transfer fluid. The fluid (usually oil) is used to generate power by means of a steam turbine or to heat up the thermal energy storage tank. Based on this technology, plants that operate with flat mirrors instead of parabolic troughs are being tested. This so-called Fresnel technology holds a further cost reduction potential, although its performance is far below the performance of parabolic troughs.

\subsection{Solar towers}

Solar towers use a large number of mirrors to concentrate the light beams onto a receiver (pointfocus) positioned in the middle of the field. The heat transfer fluid flows through the receiver, where it is heated, and is used to either generate power or be stored inside the thermal energy storage tank. Both the line-focused and tower systems should be placed in an area with intense DNI and nearby grid connection. Each of the systems needs a substantial amount of water for steam circuit operation and for keeping the reflectors clean.

\section{Geographic factors favouring CSP}

South Africa offers some of the world's best areas of high irradiation, making solar energy, especially CSP with storage, a particularly fitting technology for the its electricity supply system. In Figure 3 the direct normal irradiation of South Africa is visualised and a grid map of high voltage lines is added (black lines). An area's DNI is directly linked to the amount of electricity a plant is able to deliver in that specific area. As a consequence, South Africa can provide more power with the same reflector size than other countries.

Judging by the DNI distribution, the northwestern region is highly suitable for CSP power plants. A DNI exceeding $2500 \mathrm{kWh} / \mathrm{m}^{2}$ could result in a lower LCOE for plants located in this area.

There are, however, several other factors affecting the profitability of an energy source. The LCOE illustrates the cost-effectiveness of a certain power plant, expressed by Equation 1 (Hernández \& Martínez, 2013).

$$
L C O E=\frac{\sum_{t=1}^{n} \frac{I_{t}+M_{t}+F_{t}}{(1+r)^{t}}}{\sum_{t=1}^{n} \frac{E_{t}}{(1+r)^{t}}}
$$

This mathematical approach contrasts the investment expenditures $I_{t}$, the operation and maintenance expenditures $M_{t}$ and the fuel expenditures $F_{t}$ to the electricity $E_{t}$ generated over a certain time $t$, which represents the life-cycle time of a CSP plant.

At this point, for reasons of fairness, it has to be mentioned that issues have been raised about the validity of using LCOE as a comparison tool of different energy sources. Indeed, the LCOE does not consider the 'hidden benefits' of a project (European Solar Thermal Energy Association (ESTELA), 2016). These include factors like the lifetime of components, degradation of performance, impact of temperature on performance, 


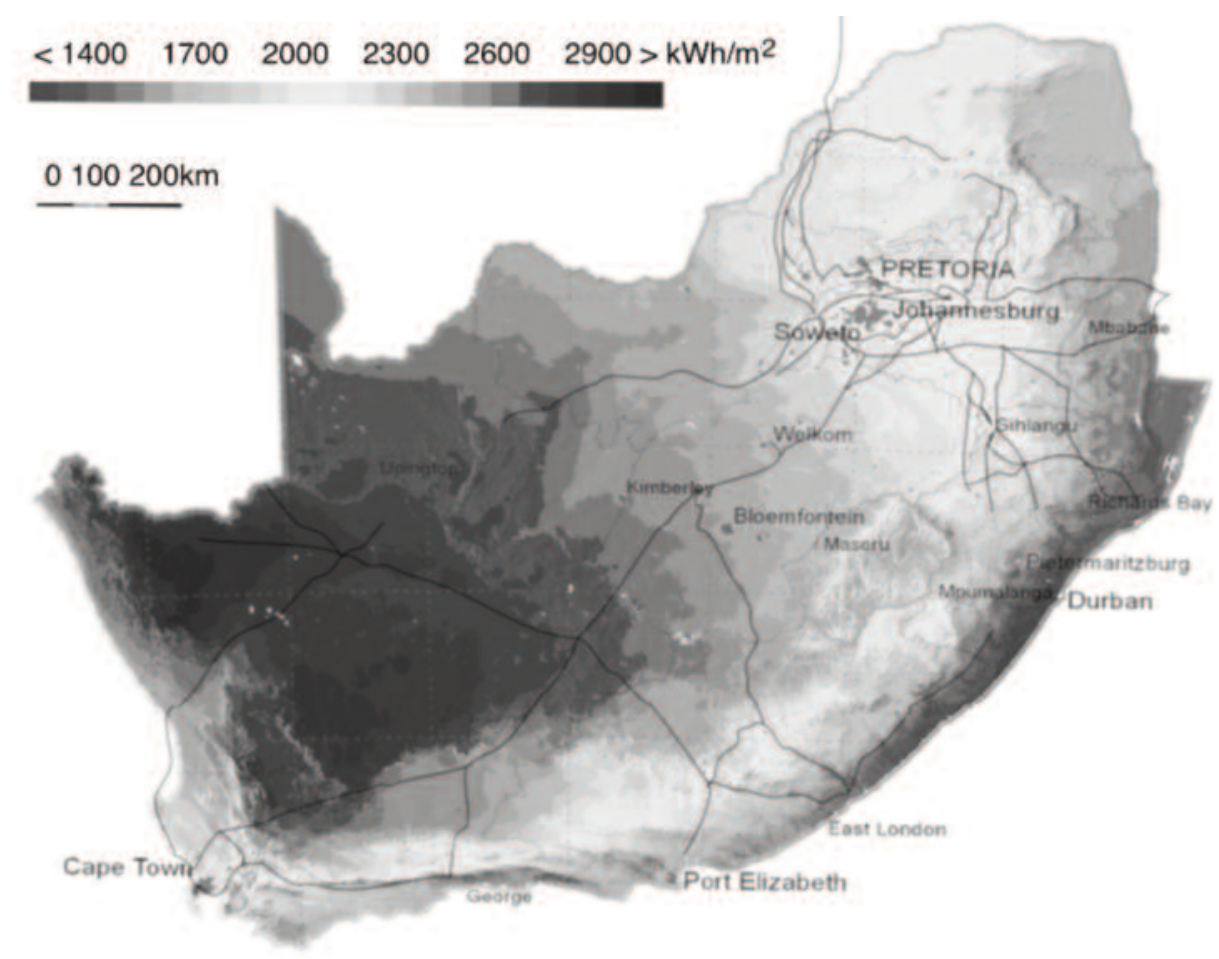

Figure 3: The DNI of South Africa with a shimmed grid map Source: GeoModel Solar (2013)

losses in charging and discharging batteries and pumping stations. The present investigation accepts and promotes the cost-vs-value approach, as introduced in the ESTELA publication, for comparing energy production means. The LCOE is, however, a widely accepted measurement of the direct, production-associated costs a power plant generates. For this reason, the LCOE is used here as a valid metric of comparison, while the feasibility of a costvs-value approach in order to incorporate hidden benefits is explicitly highlighted. Concerning the allocation problem of CSP, the ratio of electricity production and its generation costs can help to determine suitable locations for plants. In order to reduce the LCOE, efforts are made to either reduce the investment, maintenance and fuel costs of a plant or increase its electricity generation. Increasing electricity supply can be achieved by providing the power plant with a high DNI level. The correlation between the DNI a CSP plant receives and the amount of power it produces is illustrated in Figure 4.

In order to establish the correlation between generated power and DNI, as seen in Figure 4, monthly average data was collected and projected for a whole year. The result is a disproportionately high relation between increasing DNI and generated power (see $E_{t}$ in equation 1). As Figure 4 shows, the plant gains efficiency, which can be measured by Equation 2 at higher DNIs, where $W_{\text {out }}$ defines the electricity output and $W_{\text {in }}$ the irradiation input.

$$
\eta=\frac{w_{\text {out }}}{w_{\text {in }}}
$$

To apply this with respect to LCOE, a suitable choice of location in a high DNI area will lead to a lower price of electricity, provided that costs remain constant. The high DNI of South Africa provides an opportunity that is almost unique, since smaller power plants are required to produce the same amount of power a bigger plant would produce in, for example, Europe (Fluri, 2009). In other words, fewer reflectors are needed for the same design output, which leads to a better LCOE.

Figure 5 shows the suitable areas where a high DNI level is combined with a good link to the grid. These locations are along several grid lines and are shown as white lines. High costs of grid expansion means that the first CSP plants should be placed close to an existing transmission line. Only when the technology is established in South Africa would enlarging the power system structure by means of grid expansion be an option. In summary, the white lines represent possible locations concerning only the DNI and grid connection factors.

Factors other than suitable grid lines and available water supply that can affect the LCOE include fuel costs $\left(F_{t}\right.$ in Equation 1 will be equal to zero in any location) as well as maintenance and investment expenditures, which are highly area-dependent.

Maintenance costs can be subdivided into manpower costs, equipment or service costs and water costs. Two main aspects are relevant here: the plant size that is most likely to affect the manpower and equipment/service costs, and the location of the plant, which has a relatively high impact on opera- 


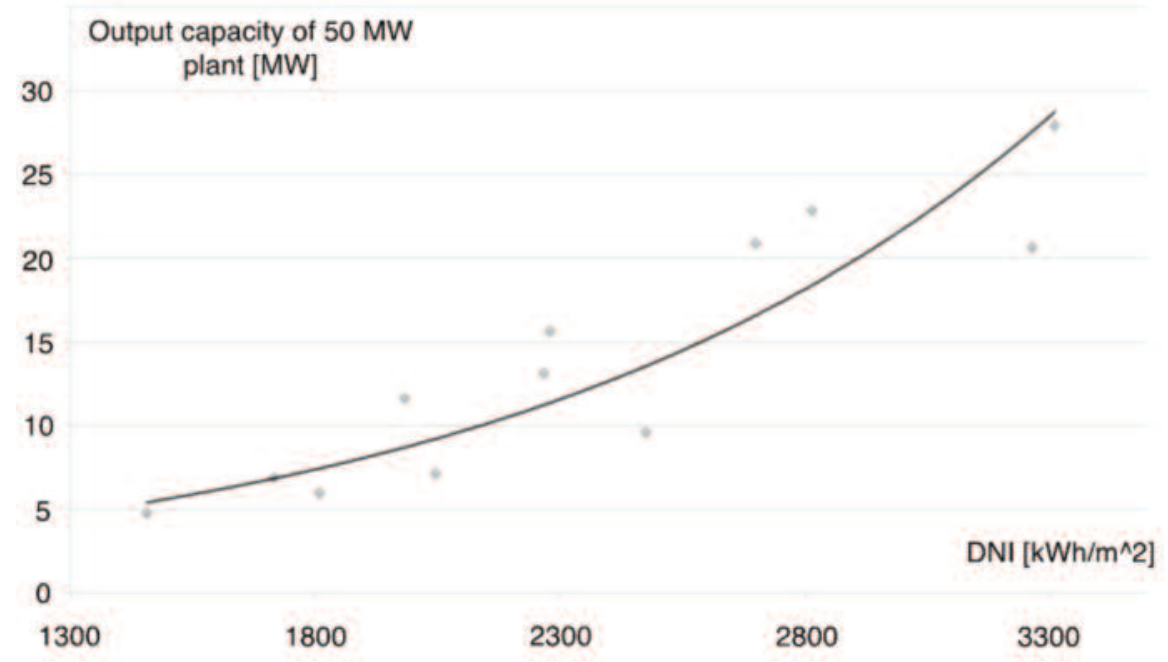

Figure 4: Correlation between generated power and DNI ${ }^{1}$ Source: Dinter et al. (2013)

tion and maintenance costs, on the basis of water availability (Braun, 2011). The demand for water to clean the reflectors and cool the generator turbine is approximately 2.9-3.6 $\mathrm{m}^{3} / \mathrm{MWh}$. Areas that combine grid connectivity with a good water supply are therefore most desirable for establishing CSP plant. In South Africa, not all rivers are perennial, so further research is needed here.

Another factor impacting the LCOE is investment cost, which is only partially influencable. In order to reduce these costs, CSP plants would be placed in an area with good infrastructure, including good transport routes, a solid basis of potential workers and operators, an almost level area to allow a stable foundation, and adequate accommodation. Furthermore, there should be no hills or mountains that could shade the reflectors and thus affect plant efficiency.

Figure 5 furthermore indicates possible plant locations in South Africa, taking into account the factors noted earlier. Locations are strongly based on solar irradiation, representing a first attempt (with the eastern part of the country excluded). More accurate analyses are required to exactly ascertain suitable CSP locations, taking into account Eskom's grid-expansion plans, political and social area-dependent discrepancies, local electricity demands and the global market situation.

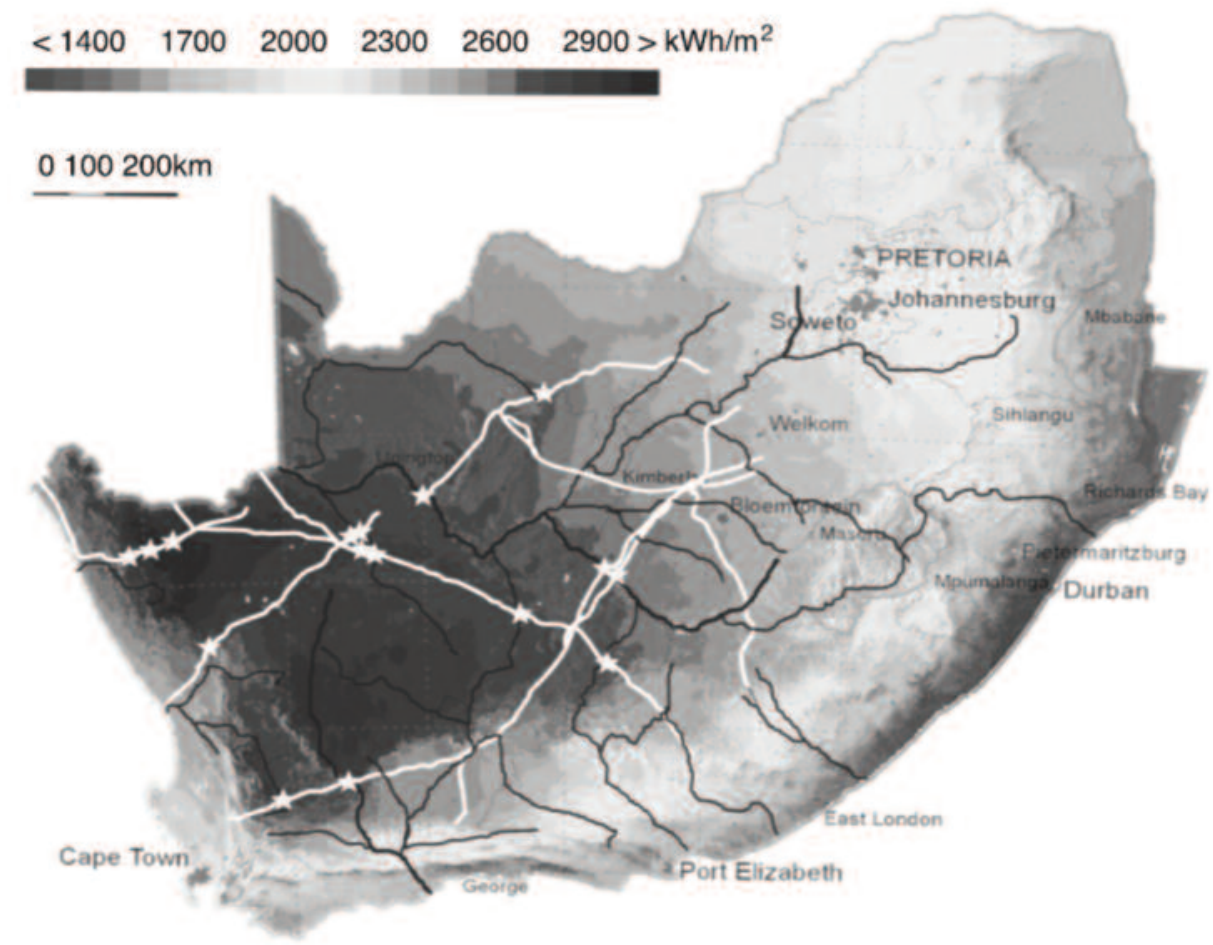

Figure 5: Map of South Africa's suitable grid lines (white) and available water supply (black) Source: GeoModel Solar (2013) 


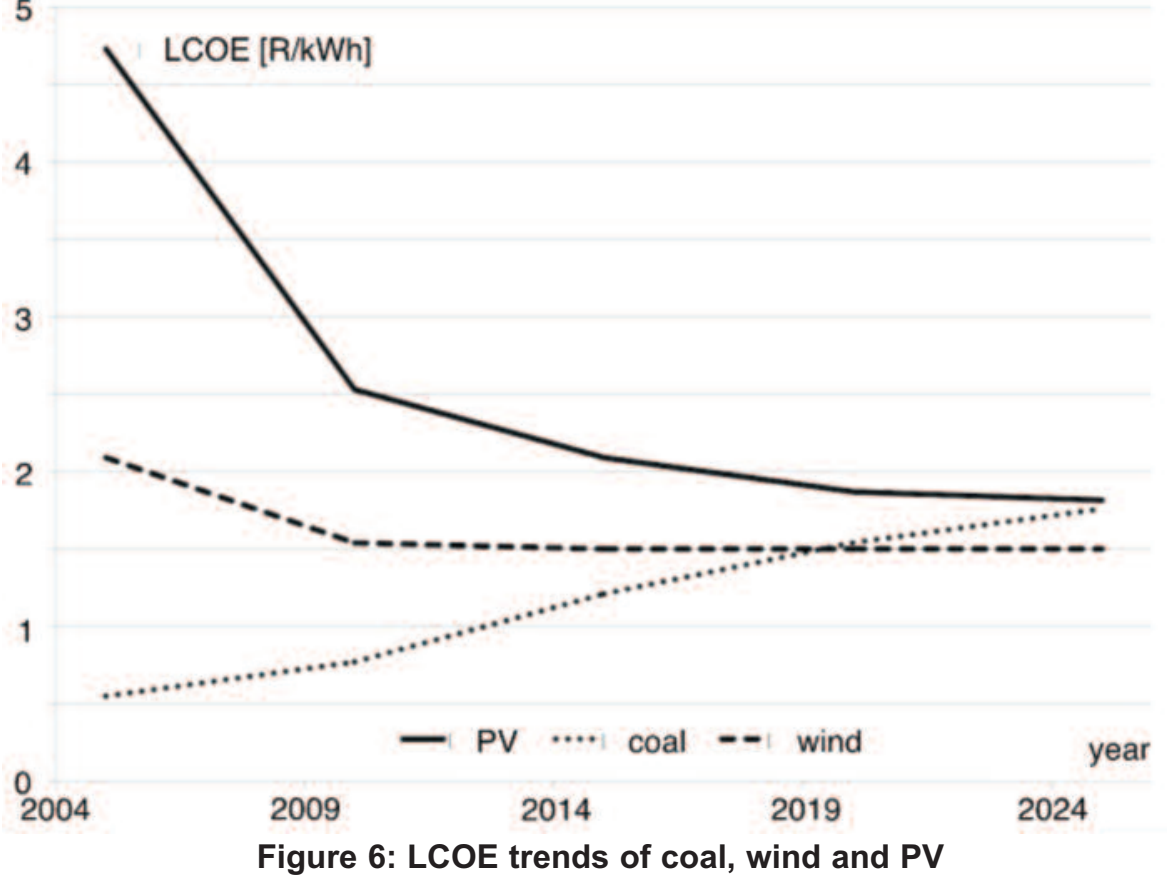

(Source: Balz et al., 2013)

\section{Economic factors favouring CSP}

Following an examination of the current situation and of possible locations of CSP plants, it is useful to turn to a consideration of future developments of CSP in South Africa, emphasising the question of whether, and to what extent, CSP could be integrated. Despite CSP still having a higher LCOE than most alternative energy sources, the present study suggests that CSP is set to become a major part of a future South African electricity system. Two aspects justify this view. Firstly, the choice of LCOE is not an instrument of actually comparing the means of energy production, but rather of highlighting the cost reduction potential of CSP. Secondly, the LCOE predictions shown in Figure 6 support the view of CSP as a feasible energy production alternative. The LCOE forecasts for the next ten years are based on several studies that analyse the cost behaviour of innovative technologies, as well as on the trend of fossil power resources. It illustrates the LCOE changes of CSP's main renewableenergy competitors: PV, wind and coal from 2004.

The wind curve is expected to be nearly constant in future because the technology is already at a later stage of maturity. The course of the PV curve is sufficiently representative of "pioneer technologies', especially in the energy sector, showing a strong cost reduction within the first decade or so, followed by smaller price cuts until it reaches a continuous state prescribed by environmental factors, commodity prices and O\&M costs. The wind energy sector has already reached that state.

The dimension of this price-decrease effect depends on the investment and the confidence associated with a specific technology. If the pioneer phase, which CSP is currently in, were followed by a strong adoption phase, it would lead to lower costs, given only a few investors. Many predictions of the LCOE trends of CSP have been made (e.g. Trieb et al, 2009 and Fawer et al, 2011), most of them leading to results similar to the average trend line in Figure 7.

The graph in Figure 7 is based on a DNI of 2500-3000 kWh $/ \mathrm{m}^{2}$. According to the Fraunhofer report studies, additional price cuts are motivated by the five essential cost-reduction potentials, which moreover represent current main research focuses:

1. Learning effects is an umbrella term for usual innovative advances. It includes improvement in efficiency and infrastructural upgrading, as well as the continuing education of workers and operators.

2. Scale-up of component production describes the procedure of settling and developing businesses, related to a specific technology. Series manufacturing and bigger production lines give cheaper component costs. Heliostats and reflectors, which make up $37 \%$ of the whole costs, are believed to profit especially from this effect.

3. Substitution of oil as heat transfer fluid by molten salt could lift the efficiency of a power plant by $12-13 \%$ due to the fact that a heatexchanging device is no longer needed to store thermal energy. The salt itself is now heated in the receiver. Researchers are currently verifying various approaches on keeping constant pipe temperatures of $>270{ }^{\circ} \mathrm{C}$ which would enable molten salt to act as a heat transfer fluid (having a melting point of $260{ }^{\circ} \mathrm{C}$ ).

4. Alternative thermal storage technologies could lead to higher storage temperatures, which go hand in hand with higher energy density and 


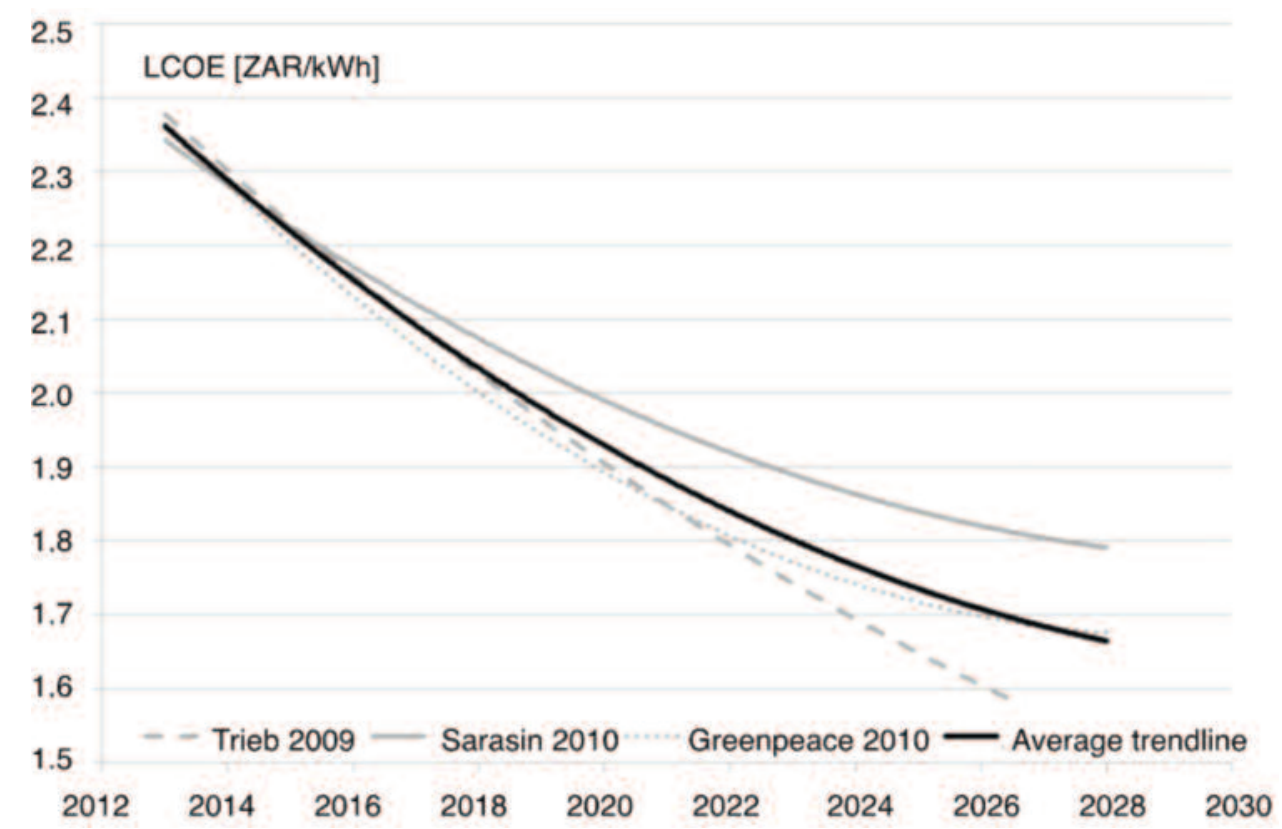

Figure 7: Predictive LCOE trend of CSP, assuming a parallel volume development of the technology Source: Fraunhofer-Institut für solare Energiesysteme (2013)

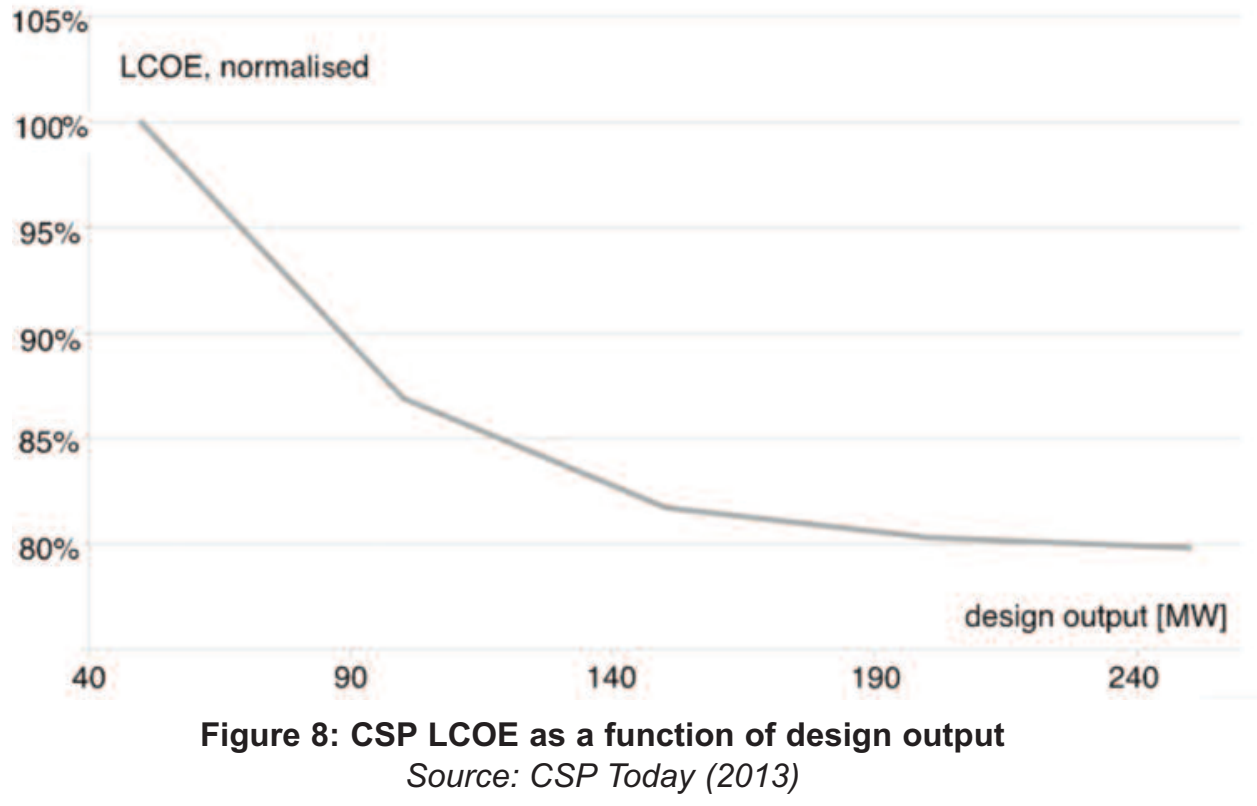

better efficiency.

5. Scale-up of plant size is believed to lead to a LCOE decrease of up to $20 \%$ (Viebahn et al, 2011). As mentioned, a plant's design output has an influence on O\&M costs, as well as investment expenditures. The costs decrease drastically, with increasing plant dimension, up to $150 \mathrm{MW}$, or even $250 \mathrm{MW}$, whereas the effect for bigger plants is not that remarkable. This is visualised in Figure 8. Reflector sizes especially are believed to have a big influence on LCOE values (CSP Today, 2013).

Fresnel technology should also be mentioned. Fresnel resorts to known line-focus technologies but features a significant difference in reflector designs.
The light is concentrated onto the receiver pipe by several small mirror bars as opposed to one big parabolic trough. Each of these mirrors is tracked and entails the possibility to work with flat surface reflectors. Flat mirrors are about four times cheaper than curved ones, offering further cost reduction potential.

A rather pessimistic cost optimisation based on these parameters could lead to a LCOE projection as shown in Figure 9. It is clear that the LCOE is already beneath the current peak-load level in South Africa, making CSP a valuable energy source for morning and evening and an immediate alternative to OCGTs. The current renewable energy feed in tariff provides a ZAR $3.94 / \mathrm{kWh}$ reward for electricity during peak hours, equal to $270 \%$ of the 


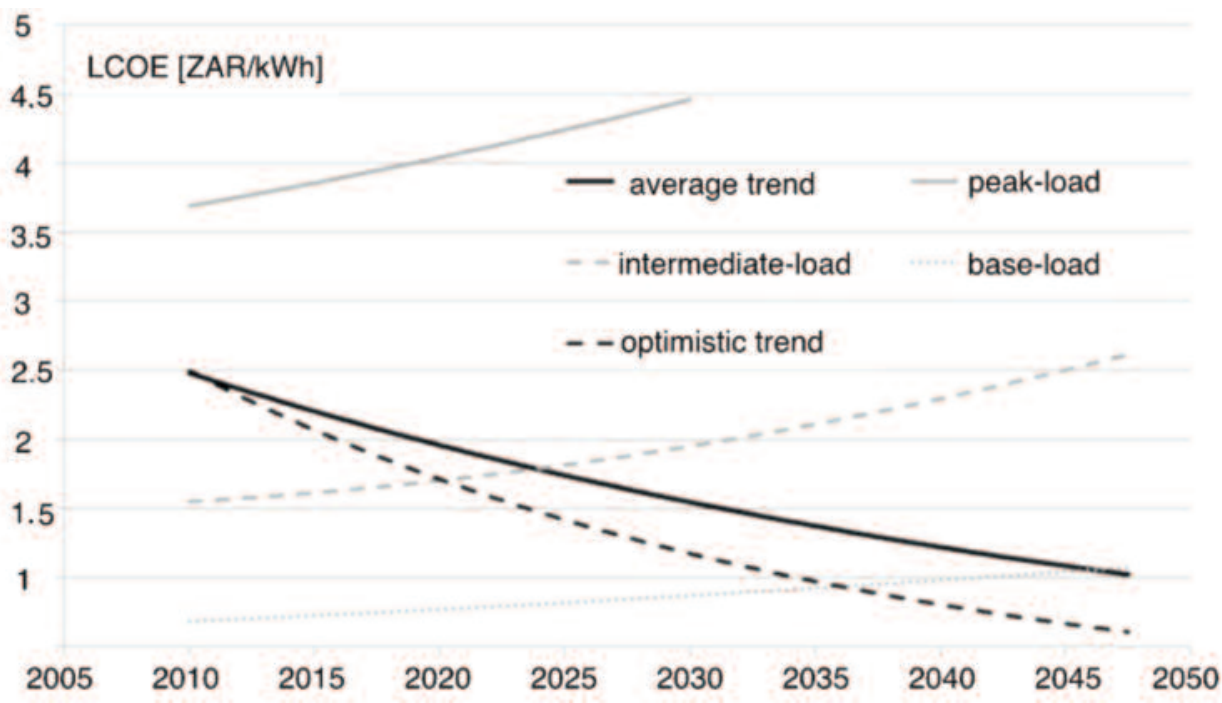

Figure 9: LCOE prediction

(Source: Silinga et al., 2013 and Müller-Steinhagen, 2013)

base-load tariff. This puts CSP in a unique position to benefit from a financial margin, since other renewables do not provide proper energy storage possibilities.

Furthermore, based on a conservative CSP LCOE trend shown in Figure 9, CSP will already match with the intermediate load around 2025. As mentioned above, this prognosis could be enhanced by an advanced adoption phase and result in lower CSP energy costs to a cost-benefit balance in 2020. The graph is partly based on a SolarPACES 2013 study (Silinga et al., 2013), which states that the current peaking LCOE shows a strong dependency on diesel costs. The LCOE of ZAR $3.69 / \mathrm{kWh}$ is based on no increase in diesel costs. An increase of $5 \%$ would result in a LCOE > ZAR $10 / \mathrm{kWh}$. As can be seen, however, the gap between CSP and OCGT costs is $1.4 / \mathrm{kWh}$, even for no increase in diesel costs. Therefore, based on Silinga et al., a peak supply turn-around towards CSP technology is the next logical step for South Africa's energy system.

The problem with the peak supply turn-around is that the LCOE will not necessarily operate as a reliable decision-making tool. Despite the advantage of LCOE, a decision in favour of CSP is accompanied by heavy investment expenditure. Comparatively, OCGTs have low investment costs, but higher O\&M costs. In addition to this, there are adequate reasons to favour CSP with storage technology to meet peak demands. As mentioned before, independence from limited resources is a major aspect of this problem. It is impossible to exactly predict diesel fuel prices, although it is certain that costs will sooner or later rise. Assuming that South Africa decides to invest in CSP this will likely result in better LCOE values, due to the cost reduction effects mentioned above.

\section{Conclusion}

Given South Africa's peak demand, CSP with storage would have substantial benefits for the country's energy system and offer a good and reasonable solution to the problem, due to the system's ability to store energy and supply electricity on demand. Peak demands go hand in hand with high electricity costs, so CSP enables a financial tolerance not shared by other energy sources.

South Africa has one of the world's highest DNI values, providing many potential plant locations along the grid lines. Due to good conducting performances of the South African power grid, it is possible to transport electricity with a loss of only $3 \%$ per $1000 \mathrm{~km}$ (Oswald, 2010), reducing the impact on choice of location. It is desirable to have good water supply and suitable infrastructure close by, and there are numerous appropriate sites, especially in the northwest. The exact location of CSP plants holds a strong cost reduction potential and should therefore be further researched.

The efficiency of a power plant scales up with increasing capacity, and the number of plants built has a decreasing effect on the LCOE; simply put, the more plants built, the less expensive they will get. The bigger the present investment and confidence in this technology, the better it will develop from a financial perspective.

The locations shown in Figure 5 represent possible plant sites in the phase for meeting peak demand, due to their low financial risks. When CSP becomes a suitable alternative for meeting intermediate load, additional locations away from grid lines could be considered. Gauché et al. (2014) suggest an addition of $3 \mathrm{GW}$ of CSP to South Africa's energy system and that the technology's significant benefits appear to vastly outweigh the risks'.

CSP would be an excellent addition to the South African energy system. Integration of this technolo- 
gy in peaking plants would be a viable alternative to current OCGTs, and it even has the potential to serve on intermediate-load level within the next ten years. This opportunity should be pursued with the necessary confidence and patience.

\section{Note}

1. Data refers to the Andasol 3 parabolic trough power plant in Spain; design output: 50 MW; storage: salt, 7.5 hours.

\section{References}

Balz, M. \& Rua, A.B. 2013. From Moses Mabhida Stadium to solar power generation in South Africa. Available: http://concentrating.sun.ac.za/wp-content/uploads/2013/12/Lecture-Markus-Balz.pdf [September 2014].

BP plc. 2013. BP Statistical Review of World Energy June 2013. Available: http://www.bp.com/content/dam/bp/pdf/statisticalreview/statistical_review_of_world_energy_2013.pdf [September 2014].

Braun, B. 2011. Wirtschaftlichkeit solarthermischer Kraftwerke (CSP) am Beispiel Desertec-Projekt unter besonderer Berücksichtigung der Clean Deveopment Mechanism

Creamer, T. 2014. Eskom weighs gas options as diesel costs double to R $10.5 \mathrm{bn}$. Available:

http://www.engineeringnews.co.za/article/eskomweighs-gas-options-as-diesel-costs-double-to-r105bn2014-07-11 [August 2014].

Aalborg CSP, 2013. Setting new standards for steam generation with Indian projects Available from: http://www.aalborgcsp.com/newsevents/newstitle/news/setting-new-standards-forsteam-generation-with-indianprojects/?tx_news_pi1[controller] $=$ News\&tx news pi

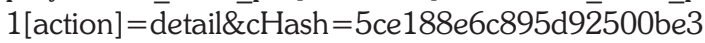
51a68ad2cf4 Accessed 5 June 2016

Department of Energy. 2011. Integrated resource plan for electricity (IRP): 2010-2030. Revision 2.

Available: http://www.DoEirp.co.za/content/IRP2010_2030_Final_Report_ 20110325.pdf [July 2012].

Department of Energy. 2013a. Integrated resource plan for electricity (IRP): 2010-2030. Update report 2013. Available: http://www.DoEirp.co.za/content/IRP2010 2030 Final_Report_20110325.pdf [December 2013].

Department of Energy. 2013b. Renewable Energy IPP Procurement Programme, Bid Window 3 Preferred Bidders' announcement, 4 November 2013. Available:

http://www.record.org.za/resources/doc_download/79 -department-of-energy-list-of-ipp-preferred-bidderswindow-3-04nov2013.pdf [December 2013].

Dinter, F., \& Gonzalez, D. M. (2013). Operability, reliability and economic benefits of CSP with thermal energy storage: first year of operation of ANDASOL 3. Energy Procedia, 49, 2472-2481.

Eskom. 2014. State of the power system quarterly update 'pre-winter'. Available:

http://www.eskom.co.za/OurCompany/MediaRoom/D ocuments/Quarterlysystemstatus25022014.pdf [September 2014].

European Solar Thermal Energy Association. 2016. The value of solar thermal electricity. Availabl: https://issuu.com/estelasolar/docs/estela_ste_value_fi nal-single [May 2016].

Fluri, T. P. 2009. The potential of concentrating solar power in South Africa. Energy Policy, 37(12):50755080.

Fraunhofer-Institut für solare Energiesysteme ISE. 2013. Stromgehstehungskosten Erneuerbare Energien Studie November 2013. Available:

http://www.ise.fraunhofer.de/de/veroeffentlichungen/veroeffentlichungen-pdf-dateien/studien-undkonzeptpapiere/studie-stromgestehungskostenerneuerbare-energien.pdf [September 2014].

Gauché, P., Brent, A.C. \& Backström, T.W., 2014. Concentrating Solar Power: Improving electricity cost and security of supply, and other economic benefits. Development Southern Africa 31(5):692-710

GeoModel Solar. 2013. SolarGIS Solar radiation maps. Available: http://solargis.info/doc/87 [December 2013].

Grobbelaar, S., Brent, A.C. \& Gauché, P. 2014. Developing a competitive concentrating solar power industry in South Africa: Current gaps and recommended next steps. Development Southern Africa. 21(3):475-493.

Hernández-Moro, J. \& Martínez-Duart, J.M. 2013. Analytical model for solar PV and CSP electricity costs: Present LCOE values and their future evolution. Renewable and Sustainable Energy Reviews 20: 119-132.

Müller-Steinhagen, H. 2013. Concentrating solar thermal power. Philosophical Transactions of the Royal Society of London A: Mathematical, Physical and Engineering Sciences. doi: 10.1098/rsta.2011.0433.

National Energy Regulator of South Africa (NERSA). 2011. Review of Renewable Energy Feed - In Tariffs (REFIT). Available:

http:/www.nersa.org.za/Admin/Document/Editor/file/ Consultations/Electricity/Presentations/Focused\%20S olar\%20Power\%20Generation\%20(SPG).pdf Accessed 16 September 2014.

Oswald, B.R. 2010. Wirtschaftlichkeitsvergleich unterschiedlicher Übertragungstechniken im Höchstpannungsnetz anhand der 380kV-Leitung Wahle-Mecklar, Leibniz Universität Hannover, Hannover.

Pegels, A. 2010. Renewable energy in South Africa: Potentials, barriers and options for support. Energy policy 38(9):4945-4954.

Robb, G. \& Roberts, S. 2014. Understanding economic regulation and competition in a developing economy: Introduction to special issue. Journal of Economic and Financial Sciences: Special Issue 7(September):501-505.

Fawer, M., \& Magyar, B. (2011). Solarwirtschaft: Hartes Marktumfeld-Kampf um die Spitzenplätze. Bank Sarasin \& Cie AG.

Silinga, C.N. \& Gauché, P. 2013. Scenarios for a South 
African CSP peaking system in the short term.

Proceedings of Solar Power and Chemical Energy

Systems conference (SolarPACES 2013), 17-20

September, Las Vegas, Nevada:32-44.

Trieb, F., Schillings, C., O'Sullivan, M., Pregger, T., and Hoyer-Klick C., (2009). Global potential of concentrating solar power. Solar Paces Conference, Berlin, Germany September 2009.

Viebahn, P., Lechon, Y., \& Trieb, F. (2011). The potential role of concentrated solar power (CSP) in Africa and Europe: A dynamic assessment of technology development, cost development and life cycle inventories until 2050. Energy Policy, 39(8):4420-4430. 